\title{
A COMPARISON OF THE METABOLISM OF FRUCTOSE AND GLUCOSE IN HEPATIC DISEASE AND DIABETES MELLITUS ${ }^{1}$
}

\author{
By LLOYD H. SMITH, JR., ${ }^{2}$ RICHARD H. ETTINGER, ${ }^{2}$ AND DAVID SELIGSON, ${ }^{2}$ \\ WITH THE TECH NICAL ASSISTANCE OF SARA LIGHTCAP \\ (From the Department of Hepatic and Metabolic Diseases, Army Medical Service Graduate \\ School, Walter Reed Army Medical Center, Washington 12, D. C.)
}

(Submitted for publication August 18, 1952; accepted December 24, 1952)

\section{INTRODUCTION}

Early interest in the comparative metabolism of fructose and glucose in diabetes mellitus was stimulated by Minkowski's demonstration that fructose produces liver glycogen readily in depancreatized dogs (1). Further studies showed that diabetic patients utilize oral fructose more readily than glucose (2). This work has been confirmed and extended by Miller, Drucker, Owens, Craig, and Woodward (3), and by Weichselbaum, Elman, and Lund (4), who have emphasized the increased production of lactate, pyruvate, and citrate during fructose infusion. Chernick and Chaikoff have demonstrated that diabetic rat liver utilizes fructose at a normal rate in vitro (5). Others have shown that fructose is utilized or converted to glycogen more efficiently than is glucose in several types of liver damage in experimental animals $(6,7)$.

The present experiments were designed to quantitate the rate of utilization of fructose in normal subjects and in patients with the decreased glucose tolerance of parenchymal liver disease and diabetes. The results indicate that fructose is utilized rapidly in normal subjects and at a nearnormal rate in the presence of marked impairment of glucose tolerance. Characteristic differences in the response of serum inorganic phosphate and of intermediary compounds of carbohydrate metabolism are demonstrated.

\section{METHODS}

Subjects for study were selected from the wards of Walter Reed Army Hospital. The normal control group was composed of laboratory personnel and patients with miscellaneous nonmetabolic disorders. The hepatitis

\footnotetext{
1 This work has been previously presented in the form of an abstract (J. Clin. Invest., 1952, 31, 663).

2 Captain, M.C.
}

group consisted of patients in the early, icteric phase of acute infectious or homologous serum hepatitis. The cirrhosis group consisted of patients with portal or postnecrotic cirrhosis ranging in clinical severity from the asymptomatic to the precoma state. One patient with severe, secondary biliary cirrhosis was included in this group. Diagnosis was established in the patients with liver disease by standard clinical and laboratory methods, and was confirmed in all cases by needle biopsy of the liver or by autopsy. All of the control subjects and the patients with liver disease were males, except for the single case with biliary cirrhosis cited above.

The patients with diabetes ranged in age from 20 to 55 years and included a broad spectrum of clinical severity. The diagnosis was established by abnormality of the intravenous glucose tolerance test, the criteria of which are defined below. These patients showed no evidence of liver disease or other detectable cause for carbohydrate intolerance. Of 14 diabetic patients studied, three of whom were females, seven were considered to have moderately severe diabetes. The mean fasting blood sugar for this group was $177 \mathrm{mg}$. per cent, and the daily insulin requirement was up to 60 units. No patient received regular insulin within 24 hours or protamine insulin within 48 hours of the test. The remaining seven diabetic patients were controlled by diet alone. In most instances the mild and the more severe diabetics reacted similarly in these studies. Where differences between the two groups were observed, they are described.

The procedure for the standard intravenous glucose tolerance test was used (8) with the subjects at bed rest before and during the test. All subjects were on a carbohydrate intake exceeding 200 grams per day and were fasted 12 to 15 hours before the tests. Glucose and fructose $^{3}$ as 10 per cent solutions were infused on successive days by constant intravenous drip at a rate of 0.5 gram per Kg. during a 30-minute period. The order of the tests was alternated between cases.

Samples of venous blood for glucose, fructose, and serum inorganic phosphate determinations were withdrawn through an indwelling needle from the opposite arm at $0,30,45,60,75,90$, and 120 minutes from the start of the infusion. The blood for glucose and fructose determinations was heparinized and preserved with potas-

3 The authors wish to express appreciation to Baxter Laboratories, Inc., Morton Grove, Illinois, for generously supplying the fructose solutions. 
sium fluoride. A Somogyi filtrate (9) was prepared to eliminate nonhexose reducing substances. Total reducing sugar was determined by the method of Nelson (10), and fructose by the Seliwanoff reaction as adapted by Roe, Epstein, and Goldstein (11). These determinations were done in duplicate with a maximal allowable variation between duplicates of 3 and 5 per cent, respectively. Blood fructose was corrected by subtracting a factor ( $0.018 \mathrm{mg}$. for each $\mathrm{mg}$. glucose) which was determined for the Seliwanoff reaction of glucose. Glucose was calculated by subtracting the fructose value from the total reducing sugar. Serum inorganic phosphate was determined by the method of Fiske and Subbarow (12) with a maximal variation of 3 per cent between duplicates. Two-hour urine specimens were collected during the tests and were measured for glucose and fructose by the above methods. Since the two-hour urine volumes usually exceeded $300 \mathrm{ml}$., spontaneous voiding was judged to be sufficient for accurate collection.

Venous blood was drawn without stasis at $0,30,60$, and 120 minutes for lactic, pyruvic, and alpha-ketoglutaric acid determinations. The samples were immediately deproteinized with tungstic acid. Blood lactic acid was determined in duplicate by the method of Barker and Summerson (13) with an allowable variation between duplicates of 8 per cent. Pyruvic and alpha-ketoglutaric acids were determined by a specific paper chromatographic separation of their respective dinitrophenylhydrazone derivatives (14).

The disappearance rate of fructose from the blood following infusion is expressed as the time to half-value, or the period of half-life. This was calculated from the formulae :

$$
\begin{aligned}
& K=\frac{\log _{0} 10}{t_{2}-t_{1}} \log \frac{C_{1}}{C_{2}} \\
& t \frac{1}{2}=\frac{\log _{0} 2}{K},
\end{aligned}
$$

where $K=$ the specific reaction-rate constant, $t=$ time in minutes, $\mathrm{C}=$ the concentration of blood fructose in $\mathrm{mg}$. per $100 \mathrm{ml}$., subscripts 1 and $2=$ the periods 45 and 90 minutes, respectively, and $t^{1} 1 / 2=$ period of half-life of fructose.

\section{RESULTS}

Glucose tolerance tests: Intravenous glucose tolerance tests were done on 15 normal controls, 11 patients with hepatitis, 10 patients with cirrhosis, and 14 diabetics. An abnormal glucose tolerance test is defined as one with blood glucose values greater than 2 standard deviations above the mean of the normal group. These upper limit values were found to be $95 \mathrm{mg}$. per $100 \mathrm{ml}$. for the fasting and 120 -minute specimens and $170 \mathrm{mg}$. per $100 \mathrm{ml}$. for the 60-minute sample. These criteria are in agreement with those of Moyer and Womack, if a 15 to $20 \mathrm{mg}$. per $100 \mathrm{ml}$. correction factor for nonhexose reducing substances is subtracted from their values (15). The blood sugar of one control subject failed to return to normal within $120 \mathrm{~min}$ utes. Three of 11 patients with hepatitis (27 per cent) and five of 10 patients with cirrhosis (50 per cent) were found to have abnormal glucose tolerance tests. The defect observed was a delayed return of blood glucose to normal levels.

Fructose tolerance tests: Fructose tolerance tests were done on 12 normal controls, 12 patients with hepatitis, 11 patients with cirrhosis, and 14 patients with diabetes. The mean blood fructose values for each group are shown in Table I. It will be noted that there were only minor differences in the mean blood fructose levels among these groups. When the curves of individual patients were plotted, it was found that the wide variations in the maximum blood levels obtained made comparison of the curves difficult.

It was found, however, that the rate of disappearance of fructose from the blood, at the levels observed in the present experiments, has the characteristics of a first order reaction. When the logarithm of the blood fructose concentration is plotted against time, a straight line relationship is obtained, as illustrated by two typical cases (Figure 1). The deviation of the 30-minute specimen from the logarithmic curve represents a distribution gradient between blood and the tissues, since constant infusion experiments by the authors have

TABLE I

\begin{tabular}{|c|c|c|c|c|c|c|c|}
\hline \multirow[b]{2}{*}{ Patients No. } & \multicolumn{7}{|c|}{ Blood fructose } \\
\hline & $0 \mathrm{~min}$. & $30 \mathrm{~min}$. & $45 \mathrm{~min}$. & $60 \mathrm{~min}$. & $75 \mathrm{~min}$. & $90 \mathrm{~min}$. & 120 min. \\
\hline $\begin{array}{ll}\text { Normal } & 12 \\
\text { Hepatitis } & 12 \\
\text { Cirrhosis } & 11 \\
\text { Diabetes } & 14\end{array}$ & $\begin{array}{r}m g . \% \quad S . D . \\
2.6 \pm 1.9 \\
1.5 \pm 1.5 \\
2.1 \pm 1.9 \\
1.8 \pm 1.6\end{array}$ & $\begin{array}{rr}\text { mg.\% } & S . D . \\
51.1 & \pm 8.1 \\
65.5 & \pm 31.2 \\
66.6 \pm 17.7 \\
58.4 \pm 18.8\end{array}$ & $\begin{array}{rr}m g . \% & S . D . \\
22.1 & \pm 4.9 \\
27.2 & \pm 10.2 \\
32.0 & \pm 8.8 \\
25.9 & \pm 7.5\end{array}$ & $\begin{array}{r}m \varepsilon . \% \quad S . D . \\
14.2 \pm 3.0 \\
16.8 \pm 6.8 \\
21.1 \pm 6.8 \\
16.9 \pm 5.0\end{array}$ & $\begin{array}{r}\text { mg.\% } \quad S . D . \\
8.6 \pm 1.9 \\
10.7 \pm 3.9 \\
13.5 \pm 4.0 \\
11.9 \pm 3.0\end{array}$ & $\begin{array}{r}m g . \% \quad S . D . \\
6.8 \pm 1.9 \\
7.6 \pm 3.5 \\
8.5 \pm 1.9 \\
8.5 \pm 2.1\end{array}$ & $\begin{array}{r}m g . \% \quad S . D . \\
4.3 \pm 1.5 \\
4.3 \pm 3.5 \\
5.5 \pm 1.9 \\
5.5 \pm 1.7\end{array}$ \\
\hline
\end{tabular}

Results of fructose tolerance tests 


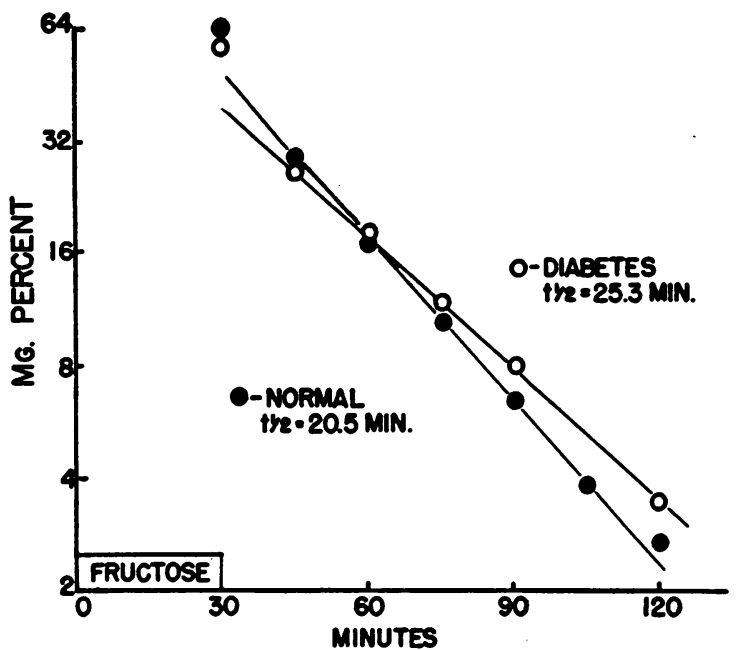

Fig. 1. Fructose Disappearance Curtes

Blood fructose levels of a typical normal person and a diabetic plotted on logarithmic scale against time.

demonstrated that tissue equilibrium is not reached until 45 minutes. These curves indicate that the rate of disappearance of fructose is directly proportional to the concentration.

As additional evidence that fructose disappearance is proportional to concentration, it was found that blood levels at equilibrium in a series of constant infusion experiments increased in approximately linear relationship to the rate of infusion (Figure 2). Since urinary excretion was

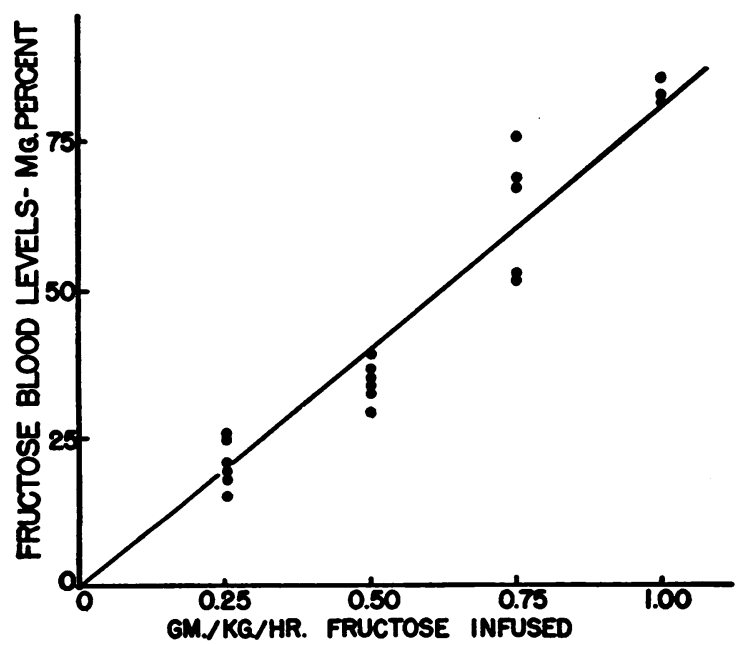

Fig. 2. Blood Levels of Fructose Maintained during Constant Infusions of Fructose at Varying Rates in a Single Individual

Illustrating a linear relationship between rate of infusion and blood level. negligible ( 0.5 to 4.0 per cent), the experiment also demonstrates that the rate of utilization (amount infused minus amount excreted) is directly proportional to the blood level.

For purposes of comparison, therefore, a fructose tolerance test can be most conveniently expressed as the period of half-life of blood fructose, as a reflection of its rate of disappearance. This method of characterizing disappearance as a slope eliminates the difficulties of comparing varying absolute blood levels. The results of half-life determinations on 49 subjects are illustrated in Figure 3. The mean value for the normal controls was 18.4 minutes with a standard deviation of 2.4 minutes. The patients with acute hepatitis and

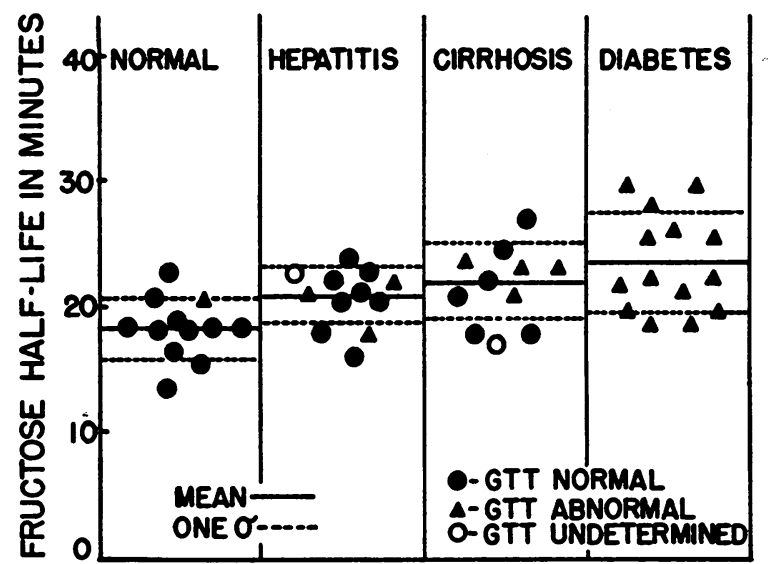

Fig. 3. Comparison of the Disappearance Rates of Fructose (Expressed as Half-Life) with Glucose TOLERANCE

Mean values (- $\longrightarrow$ ) for each group of patients and one standard deviation from the mean (-..-) are illustrated.

cirrhosis had mean half-life values of $20.8 \pm 2.3$ and $21.8 \pm 3.1$ minutes, respectively, representing prolongations of the disappearance rates of 13 and 18 per cent. These prolongations of half-life are statistically significant $(p<0.01)$. There was no correlation between abnormal glucose tolerance and fructose half-life values in these groups. The patients with diabetes had a mean half-life value of $23.6 \pm 4.0$ minutes, representing an increase of 28 per cent over normal, which is highly significant $(p<0.001)$. All of the 14 diabetic patients showed half-life values greater than the normal mean, and six had half-life values greater than 2 standard deviations above the normal mean. In 
general, the mild diabetics had slightly more rapid rates of fructose disappearance than the more severe group (mean values of 22.1 and 25.0 minutes, respectively). This difference was not statistically significant, however, and many exceptions were found. For example, a 24-year-old pregnant diabetic, who had fasting blood sugars averaging 170 mg. per $100 \mathrm{ml}$. on 60 units of insulin per day, had the lowest fructose half-life of the group (18.7 minutes).

Fructose infusion in the normal controls produced a mean rise in blood glucose of $4.0 \mathrm{mg}$. per $100 \mathrm{ml}$. at 30 minutes. This was followed by a fall in mean glucose concentration of $8 \mathrm{mg}$. per $100 \mathrm{ml}$. below the fasting level at 90 minutes and a return to the fasting level at 120 minutes. There was a marked variation in response among individuals, some exhibiting an initial fall of blood glucose. Patients with hepatitis showed similar variations. The rise was most marked in the cirrhosis group (16.1 mg. per $100 \mathrm{ml}$.) and in this group only was it statistically significant.

The failure of insulin to influence fructose utilization is illustrated in Figure 4. Invert sugar was given by constant intravenous infusion to a normal subject at the rate of 1 gram per $\mathrm{Kg}$. per hr. At 90 minutes, after a constant blood fructose level had been attained, insulin was added to the infusion at the rate of 0.4 unit per minute. A marked fall in blood glucose to $29.5 \mathrm{mg}$. per 100 ml. occurred, but the fructose blood level was not

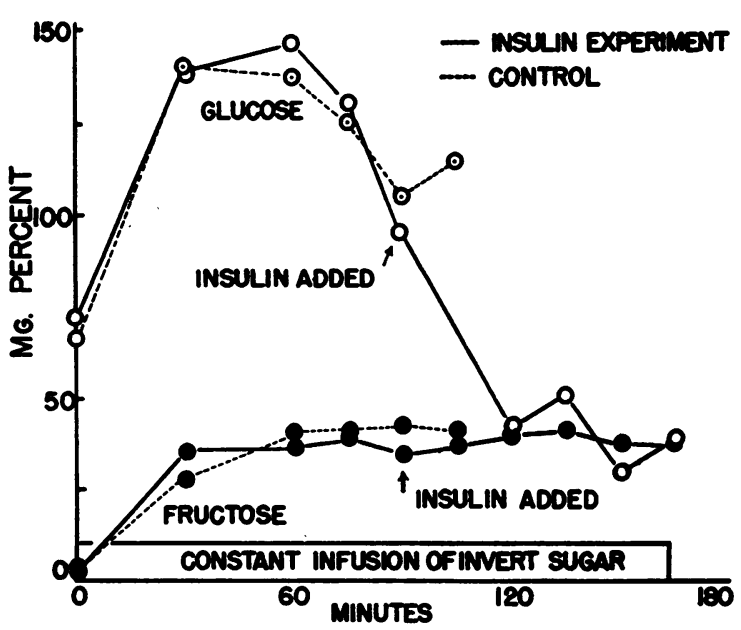

Fig. 4. EfFect of Insulin on Blood Levels of Glucose and Fructose Maintained by Constant Infusion OF INVERT SUgAR

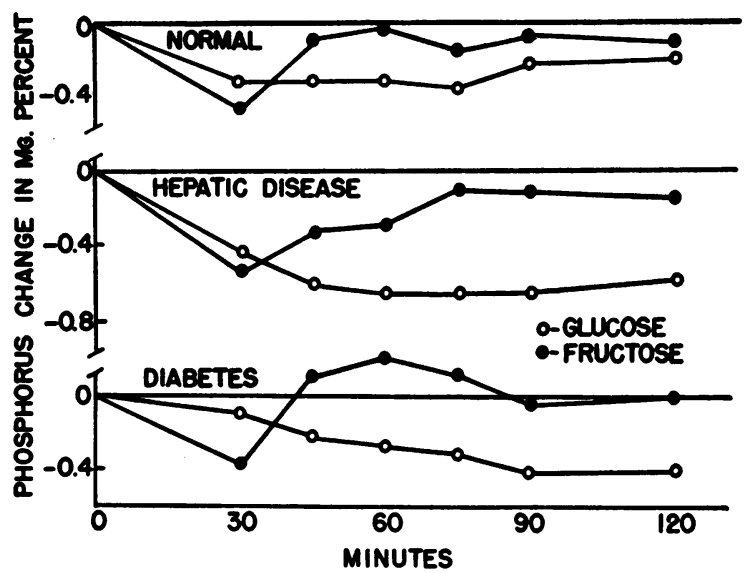

Fig. 5. Serum Inorganic Phosphate Changes from Fasting Levels in Response to Fructose and Glucose INFUSIONS

Mean values after glucose in 14 normals, 16 patients with hepatic disease and 13 diabetics; after fructose in 7 normals, 18 patients with hepatic disease and 13 diabetics.

changed. The subject experienced no symptoms of hypoglycemia.

Serum inorganic phosphate: The mean changes in the serum levels of inorganic phosphate (expressed as phosphorus) in normals, in patients with parenchymal liver disease, and in diabetics are shown in Figure 5. Since the results obtained for the hepatitis and cirrhosis groups were similar, they have been combined. Glucose produced a slow, persistent drop of phosphate in all groups, the fall being most marked in the group with liver disease. Fructose produced a more rapid fall of phosphate in all groups at 30 minutes, and a more rapid return toward normal. At all points between 45 and 120 minutes, the differences in the responses to glucose and fructose were highly significant ( $p<0.01$ to 0.001 ) in both the hepatic and diabetic groups. The phosphate fall after fructose at 30 minutes in the hepatic patients was not significantly different from those with diabetes ( 0.53 and $0.37 \mathrm{mg}$. per cent, respectively). The diabetics exhibited a more rapid return to normal, however, and the elevation of phosphate above fasting levels at 45,60 , and 75 minutes was significant.

The phosphate response to glucose infusion was compared in the mild diabetics and those patients with liver disease having a similar degree of glucose intolerance. The difference was most significant $(p<0.01)$ at 30 minutes. The mean 
phosphate fall of these hepatic patients was 0.44 mg. per $100 \mathrm{ml}$. while the mean fall for the mild diabetics was only $0.15 \mathrm{mg}$. per $100 \mathrm{ml}$. There were wide individual variations in each group: the hepatic group varied from a fall of $0.63 \mathrm{mg}$. per $100 \mathrm{ml}$. to a rise of $0.39 \mathrm{mg}$. per $100 \mathrm{ml}$., the diabetics from a fall of $0.27 \mathrm{mg}$. per $100 \mathrm{ml}$. to a rise of $0.14 \mathrm{mg}$. per $100 \mathrm{ml}$. One patient with hepatic disease fell less than the diabetic mean and none of the diabetics had a phosphate fall as low as the mean of the hepatic group.

Intermediary metabolites: The blood levels of lactic, pyruvic and alpha-ketoglutaric acids were measured during fructose and glucose tolerance tests in nine normals, six patients with hepatitis, seven patients with cirrhosis and eight patients with diabetes. Following fructose infusion, maximum blood levels of these metabolites were found at the 30-minute period; there was then a rapid return of lactate and pyruvate and a more gradual
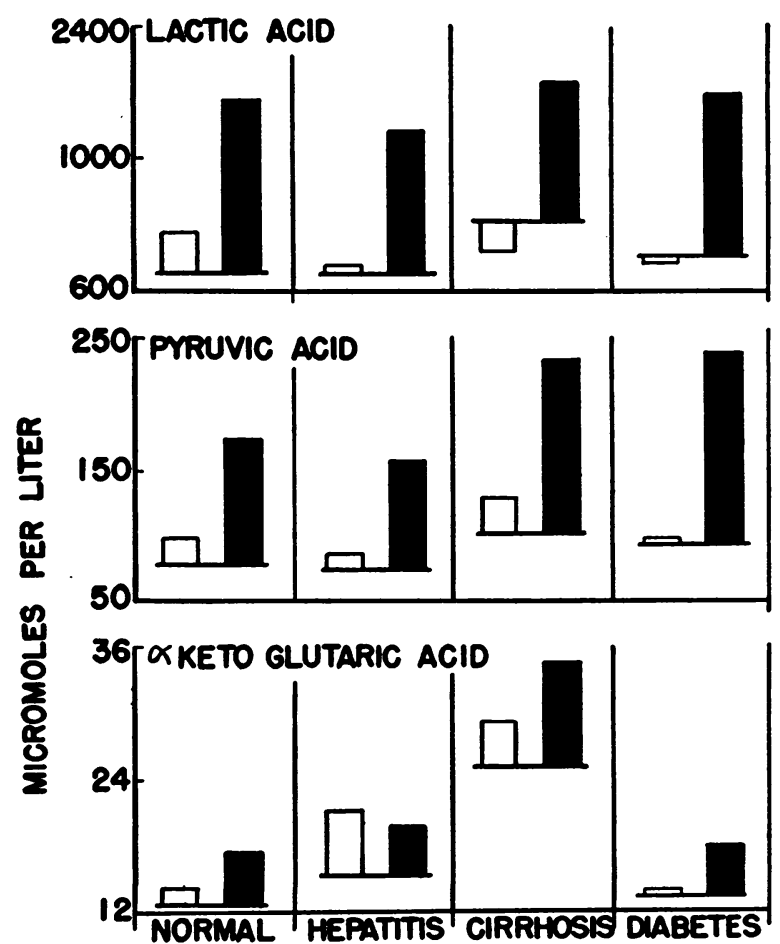

Fig. 6. Lactic Acid, Pyruvic Acid and $\alpha$-Ketoglutaric Acid Changes in Response to Glucose and FrucTOSE INFUSIONS

The mean fasting levels are illustrated by the horizontal lines. The maximal elevations following glucose and fructose infusions are shown by white and black vertical columns, respectively. return of ketoglutarate to fasting levels. After glucose infusion, however, maximum values were obtained at 60 minutes with the single exception of the lactate value in the cirrhotic patients. The mean fasting values and the highest values obtained after each infusion are shown in Figure 6.

The mean fasting level of blood lactate for the normal subjects was $720 \mu \mathrm{mol}$. per liter, with an individual variation of 475 to $1,380 \mu \mathrm{mol}$. per liter. A mean elevation of fasting level was found only in the cirrhotics $(1,070 \mu \mathrm{mol}$. per liter $)$ and the highest value observed $(2,045 \mu \mathrm{mol}$. per liter $)$ occurred in a patient of this group. Following glucose infusion there were small mean increases of blood lactate in normals and in patients with hepatitis, and small mean decreases in the patients with cirrhosis and diabetes. Fructose infusion produced a 100 to 160 per cent increase of lactate in all groups. The increase was greatest in the normal group and least for the cirrhotics.

The mean fasting blood level of pyruvate in normals was $77 \mu \mathrm{mol}$. per liter with a range of 60 to $122 \mu \mathrm{mol}$. per liter. There were no significant differences in the fasting levels among groups, although patients with cirrhosis and diabetes tended to have slightly higher values. Glucose produced a small pyruvate elevation in all groups, but least in the diabetics. Infusion of fructose was followed by pyruvate increases of 115 to 150 per cent in all groups. Although differences were not marked, the greatest elevations occurred in the diabetic and cirrhotic patients.

The constancy of the lactate/pyruvate ratio is of interest. In 224 determinations on 28 subjects varying widely in age and in disease state, and having a 600 per cent range in absolute blood levels, the mean ratio was 9.3 with a standard deviation of only 0.96 . This degree of constancy is in agreement with the work of Stotz and Bessey (16), although they reported a ratio of 12.2.

The changes in blood levels of ketoglutarate after glucose and fructose infusions were less marked than those of lactate and pyruvate. The normal fasting mean was $12.6 \mu \mathrm{mol}$. per liter, with a range of 9 to $15 \mu \mathrm{mol}$. per liter. The patients with cirrhosis exhibited a marked elevation of the fasting level, having a mean of $24.9 \mu \mathrm{mol}$. per liter with a range of 9 to $42 \mu \mathrm{mol}$. per liter. The hepatitis group had a mean fasting value of $15.4 \mu \mathrm{mol}$. per liter. All groups, except that of hepatitis, had 
TABLE II

Amounts of fructose and glucose axcreted in the urine during tolerance tests

\begin{tabular}{cccccccc}
\hline \hline & \multicolumn{3}{c}{ Fructose tolerance tests } & & \multicolumn{2}{c}{ Glucose tolerance tests } \\
\cline { 2 - 7 } Patients & $\begin{array}{c}\text { Fructose } \\
\text { excreted }\end{array}$ & $\begin{array}{c}\text { Glucose } \\
\text { excreted }\end{array}$ & $\begin{array}{c}\text { Infused } \\
\text { sugar } \\
\text { excreted }\end{array}$ & & $\begin{array}{c}\text { Fructose } \\
\text { excreted }\end{array}$ & $\begin{array}{c}\text { Glucose } \\
\text { excreted }\end{array}$ & $\begin{array}{c}\text { Infused } \\
\text { exugar } \\
\text { excreted }\end{array}$ \\
\hline Normal & grams & grams & $\%$ & & grams & 0.76 & 2.3 \\
Hepatitis & 1.30 & 0.15 & 3.8 & - & 0.46 & 1.4 \\
Cirrhosis & 1.58 & 0.24 & 4.7 & - & 1.11 & 3.0 \\
Diabetes & 1.32 & 0.41 & 3.7 & - & 4.83 & 13.6 \\
\hline
\end{tabular}

greater rises in response to fructose than glucose infusion. The degree of elevation of ketoglutarate following the infusion of fructose was less than that of lactate and pyruvate, being in the range of 30 to 40 per cent.

It was not possible to correlate either the fasting level or the degree of change of any of the intermediary compounds with glucose or fructose tolerance. It is of interest, however, that the maximum fall in phosphate did occur at the same time as the maximum rise in intermediates : 30 minutes when fructose was infused and 60 to 90 minutes when glucose was infused. There was also good correlation between fasting ketoglutarate levels and the degree of clinical, laboratory and histopathological evidence of liver dysfunction in the cirrhosis group and in patients with acute hepatitis (17). This correlation was much less striking for lactate and pyruvate in the same patients.

Renal excretion: The mean quantities of fructose and glucose excreted in the urine by each group during the tolerance tests are presented in Table II. When fructose was infused all groups excreted approximately the same amounts of fructose. Insignificant amounts of glucose were excreted during fructose tolerance tests except by the diabetics, who lost an average of 1.07 grams. This was less than the amount of fructose simultaneously excreted (1.43 grams).

When glucose was infused, approximately equal amounts were excreted by normals and patients with hepatitis and cirrhosis. The diabetic group lost an average of 13.6 per cent of the infused glucose in the urine during the tolerance tests. This represented a loss of twice as much sugar as the total of the fructose and glucose excreted during a fructose tolerance test. Four exceptions to this occurred, all among the mild diabetics. Among the non-diabetic subjects, however, there was a greater urinary loss of fructose than glucose during their respective tolerance tests.

\section{DISCUSSION}

It is recognized that the intestinal absorption of fructose is slower than glucose $(18,19)$ and that differences in absorption rates among individuals with varying disease states may also exist. Intravenous tolerance tests, therefore, were employed to facilitate comparison of the rates of utilization. The brief period of half-life obtained when fructose was infused demonstrates that the disappearance rate of fructose (and presumably its utilization ${ }^{4}$ ) was rapid. There was little variation in the half-life value among the normal subjects. The utilization of fructose was directly proportional to the blood concentration as indicated by the logarithmic disappearance curves during the tolerance tests and by the blood levels obtained at equilibrium during constant infusion experiments at increasing rates (Figures 1 and 2). This proportionality for fructose has been demonstrated at blood levels of 4 to $80 \mathrm{mg}$. per $100 \mathrm{ml}$. in these experiments. A linear relationship between glucose utilization and concentration at 200 to $600 \mathrm{mg}$. per $100 \mathrm{ml}$. has been demonstrated by Lundsgaard, Nielsen, and Orskov (22). Bouckaert and de Duve (23) confirmed this finding and have cited it as evidence that the initial reaction in glucose uptake by the tissues is "monomolecular."

4 It is appreciated that the term "utilization" may logically be challenged when reference is made to rates of disappearance. For present purposes, it may be defined as the disappearance of infused sugar not accounted for by renal excretion. That utilization actually has occurred, however, may be inferred from the increases in blood levels of the intermediaries seen in these experiments and of glycogen formation and respiratory quotient rises reported by others $(20,21)$. 
It has been stated by Weichselbaum, Elman, and Lund (4) that fructose is assimilated more rapidly by normal persons than glucose. In our group of normals, glucose returned to the fasting level more rapidly than did fructose. Although the early removal from the blood was slower than for fructose, glucose utilization proceeded more rapidly after 30 minutes because of the advantage of higher blood levels. The smaller peak rise in blood fructose is compatible with the in vitro demonstration of the greater activity of liver fructokinase than hexokinase (24). Using hepatic vein catheterization, it has been demonstrated that approximately 40 per cent of infused fructose was removed by the liver (splanchnic tissues) during a constant infusion $(4,25)$.

A number of investigators have demonstrated the superior utilization of fructose in diabetes and the failure of insulin to affect the rate of fructose utilization $(20,26,27)$. The results of the present experiments confirm these observations. Six of 14 diabetics studied had normal fructose tolerance and the remainder had only small halflife increases. It should be emphasized that the impairment of fructose tolerance in these diabetics, though statistically significant when calculated as the period of half-life, was small when contrasted to the impairment of glucose tolerance. These patients did not lose a significantly greater amount of fructose in the urine than did the normal subjects, and the total urinary sugar loss was less than that occurring when equivalent amounts of glucose were given.

The intravenous tolerance tests in patients with hepatitis and cirrhosis confirm that fructose may continue to be utilized normally in hepatic disease when glucose tolerance is impaired. The decrease in the rate of disappearance, when present, was minimal and it could not be correlated in individual patients with the degree of glucose intolerance. The oral fructose tolerance test has been used as an index of liver function $(28,29)$. In this series, a large number of icteric hepatic patients had normal intravenous fructose tolerance tests. This includes one patient with cirrhosis who was tested two weeks prior to his death in hepatic coma. As either a diagnostic or prognostic guide, therefore, the intravenous test would seem of no value.
Although changes in serum inorganic phosphate reflect only the sum of many reactions involving phosphorylation and dephosphorylation, they may be useful in following the rates of reaction of a single metabolite infused in large concentration. The data presented suggest a more rapid initial phosphorylation of fructose than glucose in all conditions studied. The more rapid return of phosphate to fasting levels also suggests the release of phosphate occurring with glycogen formation or oxidation. This would be compatible with the findings of more rapid initial disappearance of fructose and the more rapid elevations of the intermediary compounds. It is of interest that when fructose was administered the rates of fructose disappearance were grossly similar in all groups, as were the changes of phosphate and intermediary compounds.

The degree of depression of serum phosphate following intravenous administration of glucose has been advocated as an important aid in differentiating mild diabetes from the glucose intolerance of liver disease $(30,31)$. In our cases the difference between the means of these groups at 30 minutes was highly significant. The marked variation among individuals of each group, however, seriously interferes with the usefulness of this test. It was previously mentioned that only one patient of the hepatic group had a phosphate fall less than the mean of the mild diabetics, and that none of the latter had a fall of phosphate as great as the mean of the hepatic group. It would seem, therefore, that diagnostic conclusions can be made only if there is no significant fall in phosphate or if the fall is as great as the mean for the normal controls.

Relatively minor rises of blood lactate, pyruvate and ketoglutarate occurred after infusion of glucose as contrasted to the large rises following fructose. These changes after fructose were associated with a more rapid and initially greater fall of serum phosphate than after glucose. Root, Stotz, and Carpenter (32) interpreted similar data to indicate an undefined difference between the metabolic pathways of fructose and glucose. Miller and his associates (3) interpreted their findings as an indication that either fructose enters the Embden-Meyerhof scheme closer to pyruvate or that it is phosphorylated faster than glucose by its own specific kinase. 
The following experiment was performed twice to test this hypothesis. Glucose was infused into a normal subject at a rate of $1 \mathrm{gm}$. per $\mathrm{Kg}$. per $\mathrm{hr}$. until constant blood levels were obtained (45-90 minutes). During this period of equilibrium, blood levels of lactate, pyruvate, and ketoglutarate showed little change from pre-infusion levels. The infusate was then changed to fructose at the same rate. During the period when fructose blood levels remained constant, the blood levels of these metabolites were markedly elevated above their control values (increases of over 100 per cent). It is assumed that when the blood levels of the sugars being infused are constant, the rate of infusion minus the rate of excretion equals the rate of utilization. Since the excretions of both glucose and fructose in this experiment were negligible ( $<5$ per cent of that infused), it may be stated that the utilization rates of the two sugars were roughly equal. It would seem, therefore, that the differences in the levels of the intermediaries during glucose and fructose infusion could not be due to differences in rates of utilization.

A possible explanation of these differences is that there is some qualitative difference in the metabolic pathway of glucose and fructose. One example would be that glucose is oxidized all or in part by an aerobic pathway dissimilar to the classical Embden-Meyerhof scheme. Several investigators $(33-38)$ have demonstrated this pathway: glucose to 6-phosphogluconate to pentosephosphate and, presumably, to two- and threecarbon particles. Dickens and Glock (39) have demonstrated these reactions and their associated enzymes in animal tissues. Fructose, however, is presumed to enter the Embden-Meyerhof scheme and progress through the diphosphate to two threecarbon particles. Therefore, twice as many moles of pyruvate (plus lactate) should be formed from fructose. The formation of triosephosphates prior to pyruvate would require, by theory, twice as many phosphorylations as would the oxidation products of glucose by the aerobic scheme. This might account for Meyerhof's findings that the addition of adenosine triphosphate enabled brain homogenates to utilize fructose as rapidly as glucose (40).

Positive evidence of an aerobic pathway for glucose is not available in intact mammals. Such a qualitative difference in the metabolic scheme, however, might best explain the data presented by this clinical study. Further information is necessary to establish the actual existence of different metabolic schemes in man and to evaluate their quantitative importance.

\section{SUM MARY}

1. Infused fructose disappears from the blood rapidly and in a manner characteristic of a first order reaction. Utilization is proportional to concentration. When calculated as the period of half-life, the rate of disappearance is slightly decreased in hepatic disease and diabetes mellitus. There is no correlation between the rate of fructose disappearance and the degree of glucose intolerance.

2. The serum inorganic phosphate following fructose infusion falls more rapidly than when glucose is infused, and returns much earlier toward the fasting level. With glucose infusion the fall of serum inorganic phosphate is significantly greater in hepatic disease then in diabetes, but the individual variations limit the diagnostic significance of this difference.

3. The rise in blood lactate, pyruvate and ketoglutarate is much greater and more rapid with fructose than with glucose, and is of similar degree in normals, diabetics, and patients with liver disease. The rise of blood ketoglutarate is less marked than that of lactate and pyruvate.

4. The fasting blood level of ketoglutarate is significantly elevated in patients with parenchymal liver disease.

5. More fructose than glucose was excreted in the urine during respective infusions (at $0.5 \mathrm{gm}$. per $\mathrm{Kg}$. in $30 \mathrm{~min}$.) by all subjects except the diabetic patients.

6. The observed differences in rates of disappearance from the blood and the responses of serum inorganic phosphate and the intermediary compounds suggest a qualitative difference in the metabolic pathways of fructose and glucose.

\section{REFERENCES}

1. Minkowski, O., Untersuchungen uber den Diabetes Mellitus nach Exstirpation des Pankreas. Arch. f. exper. Path. u. Pharmakol., 1893, 31, 85.

2. Joslin, E. P., Root, H. F., White, P., Marble, A., and Bailey, C. C., The Treatment of Diabetes Mellitus. Lea \& Febiger, Philadelphia, 1946, 8th ed., p. 356. 
3. Miller, M., Drucker, W. R., Owens, J. E., Craig, J. W., and Woodward, H., Jr., Metabolism of intravenous fructose and glucose in normal and diabetic subjects. J. Clin. Invest., 1952, 31, 115.

4. Weichselbaum, T. E., Elman, R., and Lund, R. H., Comparative utilization of fructose and glucose given intravenously. Proc. Soc. Exper. Biol. \& Med., 1950, 75, 816.

5. Chernick, S. S., and Chaikoff, I. L., Two blocks in carbohydrate utilization in the liver of the diabetic rat. J. Biol. Chem., 1951, 188, 389.

6. Nagao, S., Experimentelle Untersuchung des Verhaltens verschiedener Heilmittel gegen die Phosphorleber, mit besonderer Berücksichtigung therapeutischer Massnahmen bei Phosphorvergiftung. Tohoku J. Exper. Med., 1934, 24, 529.

7. Okamura, S., Zuckerassimilation bei Stauungsikterus (II). (Zufuhr von verschiedenen Zuckern.) Arb. aus. d. med. Univ. Okayama, 1931, 2, 471.

8. Thorn, G. W., Koepf, G. F., Lewis, R. A., and Olsen, E. F., Carbohydrate metabolism in Addison's disease. J. Clin. Invest., 1940, 19, 813.

9. Somogyi, M., A method for the preparation of blood filtrates for the determination of sugar. J. Biol. Chem., 1930, 86, 655.

10. Nelson, N., A photometric adaptation of the Somogyi method for the determination of glucose. J. Biol. Chem., 1944, 153, 375.

11. Roe, J. H., Epstein, J. H., and Goldstein, N. P., A photometric method for the determination of inulin in plasma and urine. J. Biol. Chem., 1949, 178, 839.

12. Fiske, C.H., and Subbarow, Y., The colorimetric determination of phosphorus. J. Biol. Chem., 1925, 66, 375.

13. Barker, S. B., and Summerson, W. H., The colorimetric determination of lactic acid in biological material. J. Biol. Chem., 1941, 138, 535.

14. Seligson, D., and Shapiro, B., Alpha-keto acids in blood and urine studied by paper chromatography. Analyt. Chem., 1952, 24, 754.

15. Moyer, J. H., and Womack, C. R., Glucose tolerance. I. A comparison of four types of diagnostic tests in 103 control subjects and 26 patients with diabetes. Am. J. M. Sc., 1950, 219, 161.

16. Stotz, E., and Bessey, O. A., The blood lactate-pyruvate relation and its use in experimental thiamine deficiency in pigeons. J. Biol. Chem., 1942, 143, 625.

17. Seligson, D., McCormick, G. J., and Soborov, V., Blood ketoglutarate and pyruvate in liver disease. J. Clin. Invest., 1952, 31, 661.

18. Cori, C. F., The fate of sugar in the animal body. I. The rate of absorption of hexoses and pentoses from the intestinal tract. J. Biol. Chem., 1925, 66, 691.

19. Groen, J., The absorption of hexoses from the upper part of the small intestine in man. J. Clin. Invest., 1937, 16, 245.
20. Cori, C. F., The fate of sugar in the animal body. III. The rate of glycogen formation in the liver of normal and insulinized rats during the absorption of glucose, fructose and galactose. J. Biol. Chem., 1926, 70, 577.

21. Campbell, W. R., and Maltby, E. J., On the significance of respiratory quotients after administration of certain carbohydrates. J. Clin. Invest., 1928, 6, 303.

22. Lundsgaard, E., Nielsen, N. A., and Orskov, S. L., On the utilization of glucose and the formation of lactic acid in the isolated hind limb preparation. Skandinav. Arch. f. Physiol., 1939, 81, 20.

23. Bouckaert, J. P., and de Duve, C., The action of insulin. Physiol. Rev., 1947, $27,39$.

24. Vestling, C. S., Mylroie, A. K., Irish, U., and Grant, N. H., Rat liver fructokinase. J. Biol. Chem., 1950, 185, 789.

25. Ettinger, R. H., Giges, B., and Smith, L. H., Jr., Unpublished observations.

26. Cori, C. F., and Cori, G. T., The fate of sugar in the animal body. VIII. The influence of insulin on the utilization of glucose, fructose and dihydroxyacetone. J. Biol. Chem., 1928, 76, 755.

27. Lundsgaard, E., Nielsen, N. A., and Orskov, S. L., The carbohydrate metabolism of the isolated cat liver. Skandinav. Arch f. Physiol., 1936, 73, 296.

28. Greene, C. H., Snell, A. M., and Walters, W., Diseases of the liver. I. A survey of tests for hepatic function. Arch. Int. Med., 1925, 36, 248.

29. Stewart, C. P., Scarborough, H., and Davidson, J. N., Some observations on the laevulose tolerance test. Quart. J. Med., n.s., 1938, 7, 229.

30. Hartman, F. W., and Bolliger, A., Curve of inorganic blood phosphates during the sugar tolerance test. Significance in diagnosis and prognosis. J. A. M. A., 1925, 85, 653.

31. Forsham, P. H., and Thorn, G. W., Changes in inorganic serum phosphorus during the intravenous glucose tolerance test as an adjunct to the diagnosis of early diabetes mellitus. Proc. Am. Diabetes A., 1949, 9, 99.

32. Root, H. F., Stotz, E., and Carpenter, T. M., The respiratory quotient and blood pyruvate and lactate responses after oral ingestion of glucose and fructose in diabetes mellitus with and without insulin. Am. J. M. Sc., 1946, 211, 189.

33. Warburg, O., Christian, W., and Griese, A., Wasserstoffübertragendes Coferment, seine Zusammensetzung und Wirkungsweise. Biochem. Ztschr., 1935, 282, 157.

34. Lipmann, F., Fermentation of phosphogluconic acid. Nature, 1936, 138, 588.

35. Dickens, F., Mechanism of carbohydrate oxidation. Nature, 1936, 138, 1057.

36. Dickens, F., Oxidation of phosphohexonate and pentose phosphoric acids by yeast enzymes. I. Oxidation of phosphohexonate. II. Oxidation of pentose phosphoric acids. Biochem. J., 1938, 32, 1626. 
37. Cohen, S. S., and Scott, D. B. M., Formation of pentose phosphate from 6-phosphogluconate. Science, 1950, 111, 543.

38. Horecker, B. L., and Smyrniotis, P. Z., The enzymatic production of ribose 5-phosphate from 6 phosphogluconate. Arch. Biochem., 1950, 29, 232.
39. Dickens, F., and Glock, G. E., Direct oxidation of glucose-6-phosphate, 6-phosphogluconate and pentose5-phosphates by enzymes of animal origin. Biochem. J., 1951, 50, 81.

40. Meyerhof, O., The rates of glycolysis of glucose and fructose in extracts of brain. Arch. Biochem., 1947, 13, 485.

\section{SPECIAL NOTICE TO SUBSCRIBERS}

Post Offices will no longer forward the Journal when you move.

Please notify The Journal of Clinical Investigation, Business Office, 622 West 168th Street, New York 32, N. Y. at once when you have a change of address, and do not omit the zone number if there is one. 